\title{
Basal Bone use in Implant Dentistry is a Boon for Patients
}

\author{
Vishwanatham Balaji Gupta * \\ Private Practice, India
}

*Corresponding author: Vishwanatham Balaji Gupta, Implantologist, Pediatric Dentist, Private Practice, India

Received date: 1 August, 2021 | Accepted date: 12 August, 2021 | Published date: 16 August, 2021

Citation: Gupta VB (2021) Basal Bone use in Implant Dentistry is a Boon for Patients. J Dent Oral Epidemiol 1(1). doi https://doi.org/10.54289/JDOE2100105

Copyright: () 2021 Gupta VB, et al. This is an open-access article distributed under the terms of the Creative Commons Attribution License, which permits unrestricted use, distribution, and reproduction in any medium, provided the original author and source are credited.

\section{Editorial}

In this Modern fast forward world, implant dentistry is also growing fast.

Earlier the dental implant was having a multi-visit and delayed in treatment completion, patients have to wait 3-6 months to fix tooth on implant. Use of basal bone was less among dentists due to less training, now many mentors started training the dentist which is boon for dental patients. In these fast forward mindsets of patients, the implant dentistry is evolving at a faster rate, use of basal bone which is more stable and denser deep inside are used to quick fix the missing teeth.

Lot of research is going on to avoid ridge augmentation and multiple surgical procedures, basal implants with single piece implants and also with multi-units are also available now.

Many reputed implant companies like strawmann noble Biocare, which believes in 2 stage implant dentistry also started their research in immediate loading implant design, they changed their designs from passive to active.

Basal implants are now used to rehabilitate cancer and other resection cases

August 1st, 2021 